\title{
Improvement of Personal Credit Response Times in a Banking Institution Applying Lean Six Sigma
}

\author{
José Romero-Romero ${ }^{1}$ and Percy Castro-Rangel, $\mathrm{MSc}^{1}$ \\ 11Ingeniería Industrial, Universidad Peruana de Ciencias Aplicadas, Perú, u201316657@upc.edu.pe, pcahpcas@upc.edu.pe
}

Abstract- This paper describes the proposal to improve the personal credit response times by centralized evaluation of a banking institution applying the Lean Six Sigma methodology. For the identification of the main problem in the define phase, a Problem Prioritization Matrix, Quality Function Deployment Matrix and the process diagram were used. In the Measure phase, the process performance was quantified using value stream mapping, Cause-Effect and Pareto Diagrams to identify input variables and the repeatability and reproducibility test for the measurement system. In the Analyze phase, root causes were identified by process analysis through Waste Identification and Data Analysis through Variance Analysis. In the Improve and Control phases, the Lean and Six Sigma tools for process analysis and data analysis were developed. With the implementation of the proposed methodology, the following results improvements were obtained reflected in reductions of: response times in $56.16 \%$, process activities in $14.29 \%$, times in material supply routes in $83.33 \%$, waiting time to be evaluated an application in $99.56 \%$ and the annual cost to execute the centralized evaluation process in $61.21 \%$.

Keywords-Lean Six Sigma, DMAIC, 5S's, Standard Work, Value Stream Mapping, Analysis of Variance, Design of Experiments.

\section{INTRODUCTION}

The bank under study is dedicated to placing different types of loans according to their type of segment, but to chart their placement, the pace of evolution of loans to the private sector in 2018 was studied, as seen in Figure 1; loans granted by banks, financiers, and municipal and rural savings banks accelerated from 6.7\% growth in December 2017 to 8.3\% at the end of 2018 [1].

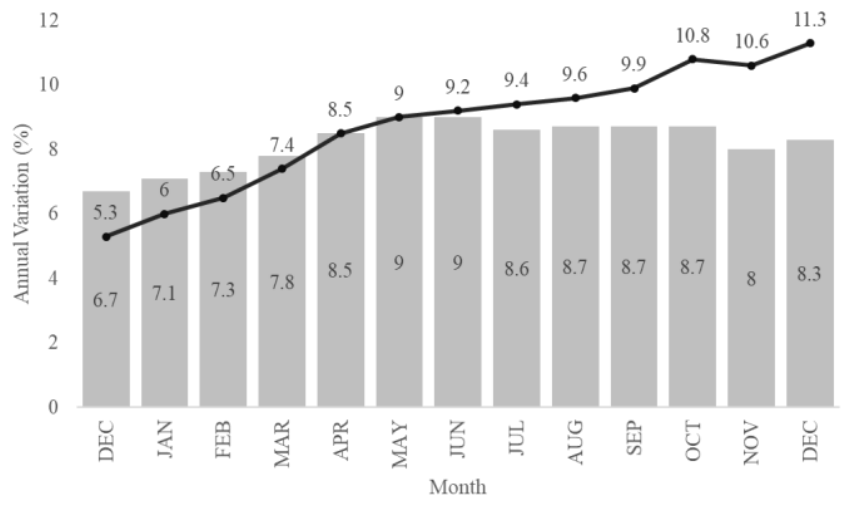

Fig. 1 Total credit to the private sector

It is verified that among the factors that influenced the total growth of loans to the private sector was the individual client segment, through mortgage credit and consumer credit with $8.8 \%$ and $12.5 \%$, respectively, at the end of 2018 [1].

Digital Object Identifier (DOI):

http://dx.doi.org/10.18687/LACCEI2020.1.1.152

ISBN: 978-958-52071-4-1 ISSN: 2414-6390
TABLE I

CRedit to Private Sector By Placement Type

\begin{tabular}{|c|c|c|c|c|c|}
\hline ID & & Dec.16. & Dec.17. & Nov.18. & Dec.18. \\
\hline 1 & Credit to enterprises & 4.7 & 5.5 & 6.1 & 6.7 \\
\hline \multicolumn{2}{|c|}{$\begin{array}{l}\text { Corporate and large } \\
\text { enterprise }\end{array}$} & 4.6 & 6.2 & 7.7 & 8.8 \\
\hline \multicolumn{2}{|c|}{ Medium enterprises } & 2.6 & 0.6 & 2.6 & 3.8 \\
\hline \multicolumn{2}{|c|}{$\begin{array}{l}\text { Small and micro } \\
\text { enterprises }\end{array}$} & 7.7 & 9.5 & 6.3 & 5.0 \\
\hline & Credit to individuals & 7.1 & 8.6 & 11.1 & 11.0 \\
\hline \multicolumn{2}{|c|}{ Consumer } & 8.7 & 8.8 & 13.1 & 12.5 \\
\hline \multicolumn{2}{|c|}{ Mortgage } & 4.9 & 8.5 & 8.2 & 8.8 \\
\hline & Total & 5.6 & 6.7 & 8.0 & 8.3 \\
\hline \multicolumn{2}{|c|}{ National currency } & 7.2 & 5.3 & 10.6 & 11.3 \\
\hline \multicolumn{2}{|c|}{ Foreign currency } & 2.0 & 9.9 & 1.8 & 1.5 \\
\hline
\end{tabular}

From the results shown in the Table 1, in the placement of consumer and mortgage loans, the financial sector has become a purely competitive environment, and thus, there is a need for banking institutions to have more flexible credit evaluation processes to efficiently meet demand both in response time and in placements [2].

Lean methodology focuses on eliminating waste with the final aim being to produce a product or provide a service in the amount required by the client, when and where the client requests it, without producing waste [3]. The Six Sigma methodology is an integrated set of technical and statistical tools that help achieve the philosophy of total customer satisfaction through reducing process variability by increasing its capacity [4].

\section{STATE OF THE ART}

Maqbool et al. [5] state that the Lean philosophy has received considerable attention from professionals and researchers since its introduction by the Toyota manufacturing system by Taiichi Ohno, because it is a concept where activities without added value (overproduction excessive processing, unnecessary inventory, unnecessary motion, excessive transportation, product defects, waiting time) can be reduced by the successful implementation of Lean practices.

Jiju et al. [6] mention that the Six Sigma process improvement methodology has been accepted globally throughout the service industry. In the last decade, the application and success of Six Sigma in services is notable in all information technology, hospitality, business, government organizations, healthcare companies, and the banking and financial sector.

Ruben et al. [7] state that Lean Six Sigma (LSS) is a powerful business strategy that offers the synergistic benefits of Lean Manufacturing and Six Sigma. The LSS improvement 
process clearly aims to integrate human and process elements to provide a clear focus to achieving final results.

Fadoua [8] states that currently, Lean management is increasingly demonstrating its legitimacy in services, especially in the banking sector. In fact, banking institutions constitute an interesting field of action for implementing the Lean Service approach, demonstrating an improvement in their processes.

Sunder et al. [9] indicate that research literature on LSS reveals a wide scope for applying theories and methodologies of operations management in banking and financial services. Tangible benefits include the improvement of KPIs, cost savings, and greater process efficiency. Intangible benefits include employee satisfaction and morale, the creation of a culture of continuous improvement, and a facilitator for learning and staff training.

Sunder et al [10], indicate that Lean is applied more frequently outside the manufacturing sector, especially in service companies. As a successful continuous improvement strategy; Lean has demonstrably helped organizations achieve quality time and quantity delivery of services to satisfy customers.

Sunder [11] indicates that using the Lean and Six Sigma combination in all services, especially in banking and finance, has been increasing in recent years. For instance, Bank of Montreal, American Express, HSBC Holdings, Bank of America, and Capital-One are some of the many banking institutions that have established LSS programs to advance the excellence of their processes. The author proposes a model as part of the study that helps LSS project managers overcome identified challenges. The model highlights three different levels of stakeholder management in LSS projects: inform, involve, and influence shown in Figure 2.

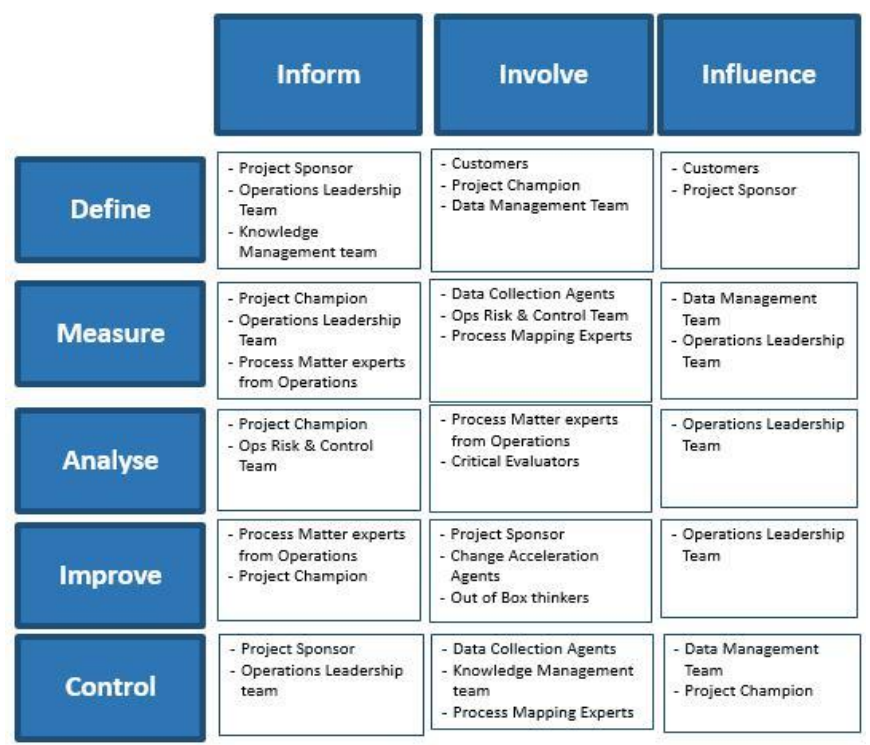

Fig. 2 Inform-Involve-Influence "31" Model for Stakeholder Management
Initially, a general assessment was made of the personal credit response times that are sent to the centralized evaluation of the 769 bank offices through sales and service advisors, and with the information obtained, a detailed process was made, along with process and data analysis.

Lastly, the innovative proposal to combine Lean and Six Sigma for the banking institution was implemented, obtaining improvement in the process results through the LSS methodology. The results obtained before and afterwards are compared.

\section{Methodology}

The innovative technical proposal shown in Figure 3 is to design a methodology based on the implementation of LSS; Lean for process analysis and Six Sigma for data analysis in the banking institution under study, which is detailed below [12].

\section{A. Define}

The first phase deals with collecting the VOC (i.e., voice of the customer) through surveys, interviews, and so on, followed by writing the project letter. The project metrics to improve are identified in this phase together with the validation of the LSS project framework with the level's project champion, that is, the management representative that will participate to provide support at the project's production level.

\section{B. Measure}

The second phase includes collecting data, mapping the process, evaluating the measurement system, and calculating the process capacity. Reference data collection plan, normality tests, control charts, defects per million opportunities or calculation of parts per million (PPM) with Cpk and Ppk values, and repeatability and reproduction test are some of the LSS tools that were used in this phase.

\section{Analyze}

The third phase deals with identifying the root causes of the problem. Together with the project manager, operation process analysts (subject matter experts) played an important role in this phase. Brainstorming, data collection for causes, Pareto analysis, hypothesis testing, Gemba, value flow allocation, fishbone diagram, and five whys analysis are some of the LSS tools used in this phase.

\section{Improve}

The fourth phase consists of identifying improvements, validating the improvement plan with stakeholders, obtaining budget approvals, and implementing process changes. Senior management, project champion, and sponsors play a vital role in this phase. Brainstorming, designing experiments, cost benefit analysis, and error tests are some of the LSS tools used in this phase.

\section{E. Control}

The fifth phase is implementing correct controls to maintain improvements and documenting the lessons learned 
from the project. This phase also validates the process improvements provided by the project with a comparison of the "before" and "after" project metric performance. Control charts, the control plan, and study of the process capacity are some of the tools used. This phase marks the closure of the LSS project.

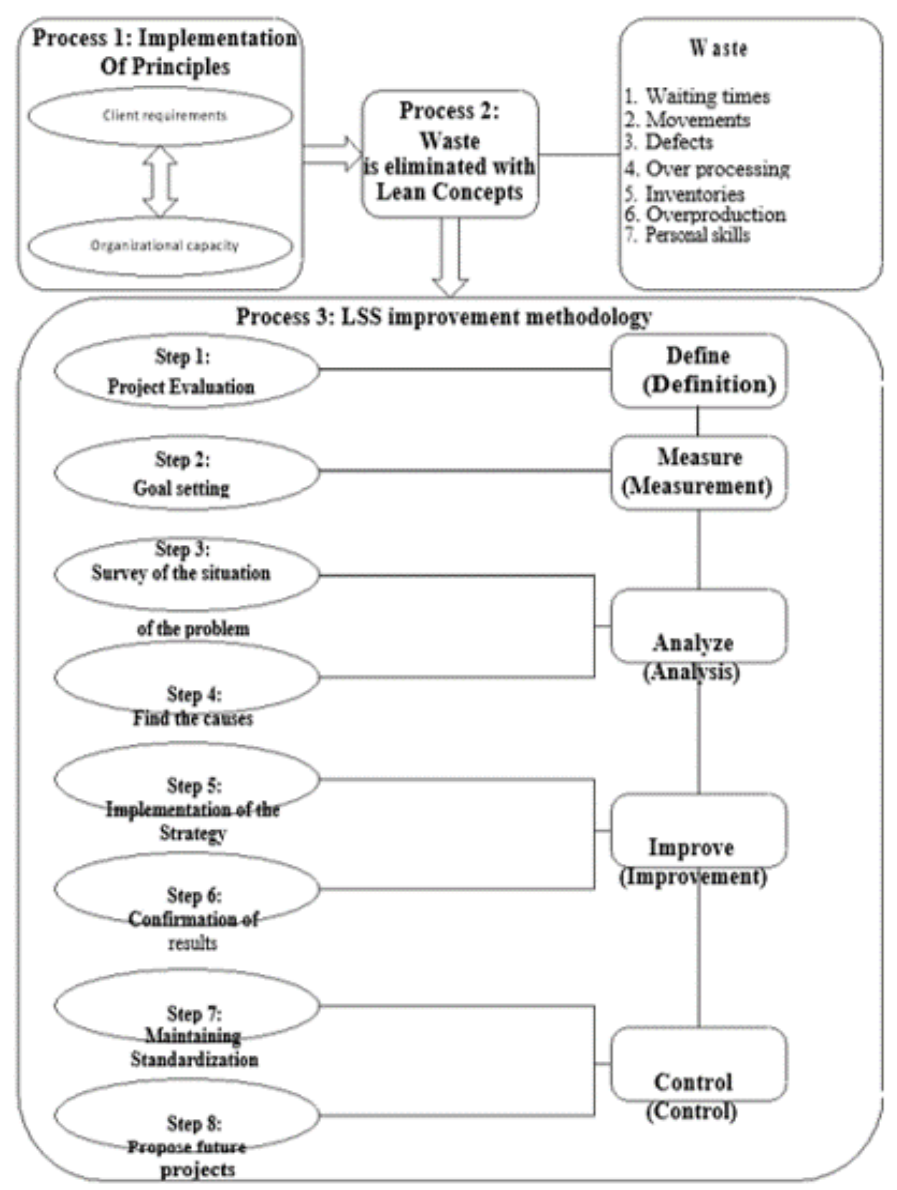

Fig. 3 Proposed LSS Mode

\section{RESULTS}

\section{A. Results before the intervention}

Problem focuses on the high response times for personal credit in the referral process to the centralized evaluation from the banking institution; this has repercussions not only on loan placements but also on the costs of executing it. This can be verified in Figure 4, which shows that $68 \%$ of problems in personal credit are referred to centralized evaluation [12].

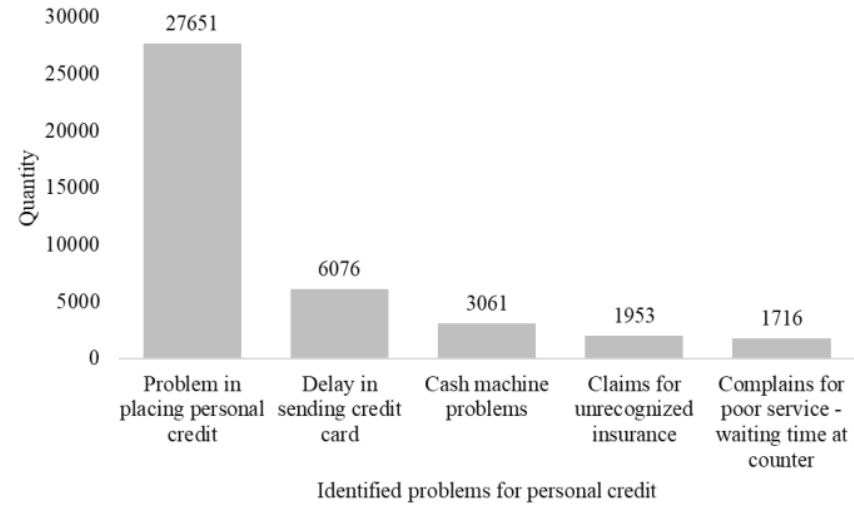

Fig. 4 Main Problems in Banking Agency, Year 2018

Likewise, an analysis process capacity was carried out. As verified in Figure 5, the potential capacity index (Cp) is $0.14<$ 1 , which means that it is not a capable process. Additionally, a negative real capacity index $(\mathrm{Cpk})-0.17$ indicates that the process average is outside the specifications or tolerances provided by the credit process efficiency area, considering a lower limit of 2380 and an upper limit of 2407 minutes.
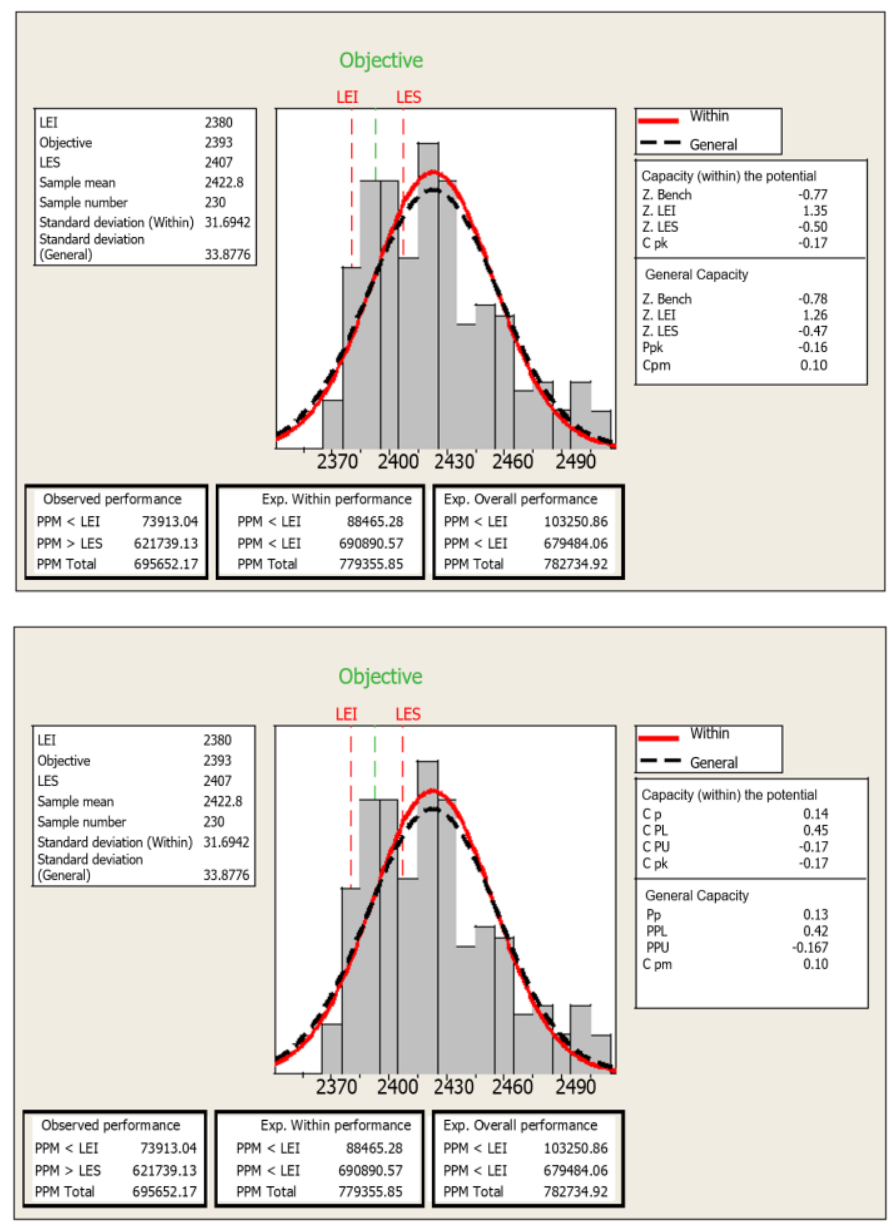

Fig. 5 Analysis of Process Capacity 
The time was then taken using a standard time study sheet; the results are shown in Table 2 .

Table 2 verifies that the current standard process time in centralized evaluation for personal credit is 2393 minutes. Additionally, the spaghetti diagram was performed in Figure 6 to determine the run time to stock up on the materials needed to execute the referral process to centralized evaluation.

TABLE II

CuRrent Personal CREDit Time In CENTRALIZEd Evaluation

\begin{tabular}{|c|l|c|}
\hline ID & \multicolumn{1}{|c|}{ Steps } & Time (min.) \\
\hline 1 & Client Evaluation Time & 7 \\
\hline 2 & Documentation Verification & 5 \\
\hline 3 & $\begin{array}{l}\text { Enter information into the Personal Credit } \\
\text { Evaluation System }\end{array}$ & 3 \\
\hline 4 & $\begin{array}{l}\text { Verification if Evaluation is Necessary by Banking } \\
\text { Agency }\end{array}$ & 6 \\
\hline 5 & Verification of Documentation to Refer & 5 \\
\hline 6 & Completion of Personal Credit Application & 45 \\
\hline 7 & $\begin{array}{l}\text { Auto-generated Code Creation for Centralized } \\
\text { Evaluation Pouch }\end{array}$ & 3 \\
\hline 8 & Put Documentation into the Referral Envelope & 7 \\
\hline 9 & Sent to Centralized Evaluation by Courier & 904 \\
\hline 10 & $\begin{array}{l}\text { Centralized Evaluation Validates the Documentation } \\
\text { Conforms }\end{array}$ & 15 \\
\hline 11 & $\begin{array}{l}\text { Centralized Evaluation Proceeds with the Evaluation } \\
\text { of the Personal Credit Application }\end{array}$ & 1,389 \\
\hline 12 & Advisor informs the clients the results & 3 \\
\hline 13 & $\begin{array}{l}\text { Proceed with the Signature for the Disbursement } \\
\text { Document Signature. }\end{array}$ & 6 \\
\hline 14 & $\begin{array}{l}\text { Proceed with the Payment of Personal Credit into } \\
\text { the Client's account. }\end{array}$ & 4 \\
\hline TOTAL & 2393 \\
\hline
\end{tabular}

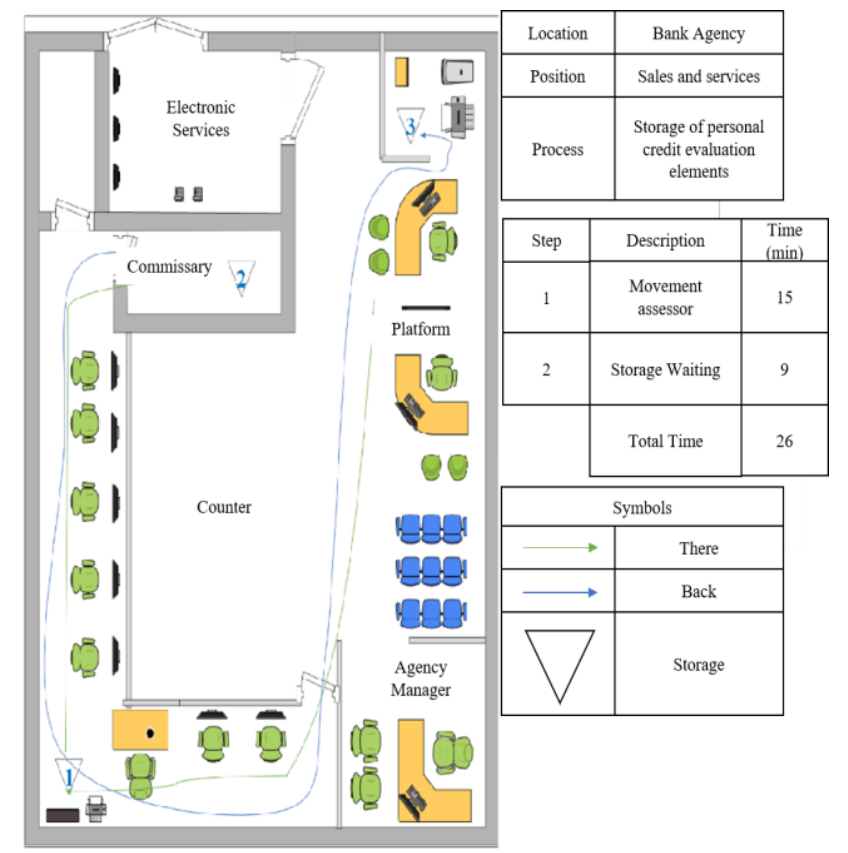

Fig. 6 Current Stock Runtime Spaghetti Diagram - from the Sales and Service Advisor
Regarding the amount of personal credit applications that can be addressed in centralized evaluation, it is verified through the Arena software simulation, that 16 requests arrive at the agency from which only three get referred to centralized and only one is attended to.

Lastly, it is verified in the Table 3 that in 2018, the Administrative Expenses of Referring to Centralized represented S /. 1,748,195.00, with the cost of sending applications by pouch being $58.59 \%$ of its total.

TABLE III

ADMINISTRATION EXPENSES OF REFERRAL APPLICATIONS, YEAR 2018

\begin{tabular}{|l|c|c|}
\hline Administrative Expenses of Referral Applications Year 2018 & S/ & $\mathbf{\%}$ \\
\hline Costs of sending requests by pouch & $1,024,210.00$ & $58.59 \%$ \\
\hline Costs of returning requests by observation & $333,989.00$ & $19.10 \%$ \\
\hline Cost of A4 sheets to print requests & $90,820.00$ & $5.20 \%$ \\
\hline Cost of printing requests & $71,836.00$ & $4.11 \%$ \\
\hline Cost of evaluation forms & $61,329.00$ & $3.51 \%$ \\
\hline Cost of envelopes for referral requests & $56,314.00$ & $3.22 \%$ \\
\hline Cost of security seals & $54,954.00$ & $3.14 \%$ \\
\hline Cost of labels for referral requests & $54,743.00$ & $3.13 \%$ \\
\hline Administrative Expenses of Referring to Centralized & $\mathbf{1 , 7 4 8 , 1 9 5 . 0 0}$ & $100.00 \%$ \\
\hline
\end{tabular}

\section{B. Results after the intervention}

Improvements in process results are obtained because of implementing the following Lean tools for process analysis: Identification of the seven wastes, $5 \mathrm{~S}$, standard work, value stream mapping, and for data analysis, the designing experiments statistical tool is used to minimize response times to personal credit requests in centralized evaluation from the financial institution under study.

The first improvement is seen in the decrease in response times from 2393 minutes to 1049 minutes, as shown in Fig. 7.

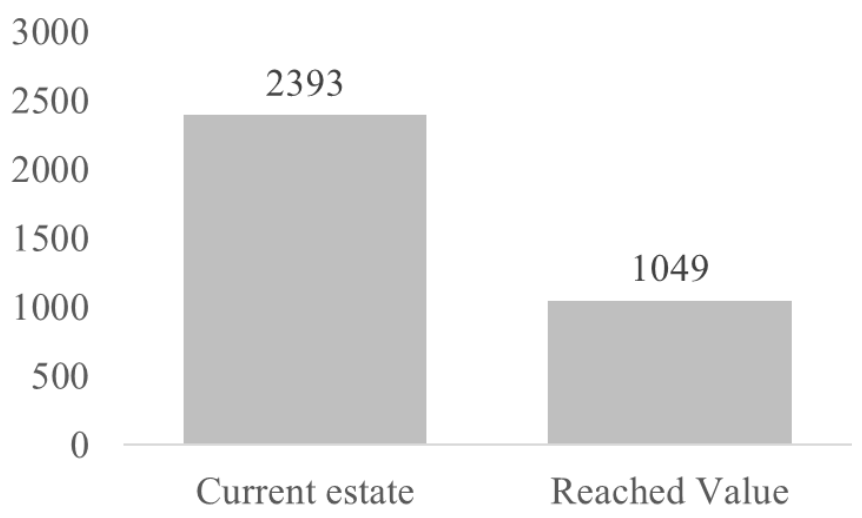

Fig. 7 Decrease in Cycle Process Production TIme

The time of 1049 minutes was achieved by eliminating waste and activities that do not add value, as the physical referral activity is now sent virtually.

The second improvement is verified in the Table 4, as it was achieved by reducing 14 activities to 12 . This process is leaner compared to the previous one. 
TABLE IV

SimplificAtion of the Process (Previous State AND Proposed STATE)

\begin{tabular}{|c|c|c|c|}
\hline ID & Steps & $\begin{array}{l}\text { Current } \\
\text { Situation } \\
\text { (min.) }\end{array}$ & $\begin{array}{l}\text { Future } \\
\text { Situation } \\
\text { (min.) }\end{array}$ \\
\hline 1 & Client Evaluation Time & 7 & 5 \\
\hline 2 & Documentation Verification & 5 & 5 \\
\hline 3 & $\begin{array}{l}\text { Enter information into the Personal } \\
\text { Credit Evaluation System }\end{array}$ & 3 & 3 \\
\hline 4 & $\begin{array}{l}\text { Verification if Evaluation is Necessary } \\
\text { by Banking Agency }\end{array}$ & 6 & 6 \\
\hline 5 & $\begin{array}{l}\text { Verification of Documentation to } \\
\text { Refer }\end{array}$ & 5 & 5 \\
\hline 6 & $\begin{array}{l}\text { Completion of Personal Credit } \\
\text { Application }\end{array}$ & 45 & 20 \\
\hline 7 & $\begin{array}{l}\text { Auto-generated Code Creation for } \\
\text { Centralized Evaluation Pouch }\end{array}$ & 3 & 0 \\
\hline 8 & $\begin{array}{l}\text { Put Documentation into the Referral } \\
\text { Envelope }\end{array}$ & 7 & 0 \\
\hline 9 & $\begin{array}{l}\text { Sent to Centralized Evaluation by } \\
\text { Courier }\end{array}$ & 904 & 4 \\
\hline 10 & $\begin{array}{l}\text { Centralized Evaluation Validates the } \\
\text { Documentation Conforms }\end{array}$ & 15 & 14 \\
\hline 11 & $\begin{array}{l}\text { Centralized Evaluation Proceeds with } \\
\text { the Evaluation of the Personal Credit } \\
\text { Application }\end{array}$ & 1,389 & 974 \\
\hline 12 & Advisor informs the clients the results & 3 & 3 \\
\hline 13 & $\begin{array}{l}\text { Proceed with the Signature for the } \\
\text { Disbursement Document Signature. }\end{array}$ & 6 & 6 \\
\hline 14 & $\begin{array}{l}\text { Proceed with the Payment of Personal } \\
\text { Credit into the Client's ccount. }\end{array}$ & 4 & 4 \\
\hline \multicolumn{2}{|c|}{ TOTAL } & 2393 & 1049 \\
\hline
\end{tabular}

The third improvement was obtained using the $5 \mathrm{~S}$ tool in the agency layout shown in Figure 6. As there was a 15minute movement time for the sales and services advisor to supply the materials for the process and a 9-minute wait time for stock up. With the proposed spaghetti diagram in Figure 8, the consultant's movements are reduced to three minutes, resulting from moving the printer into an intermediate place between the platform boxes. With respect to the supply time, it was reduced by 1 minute, as the forms and bond sheet were moved into the warehouse next to the platform.

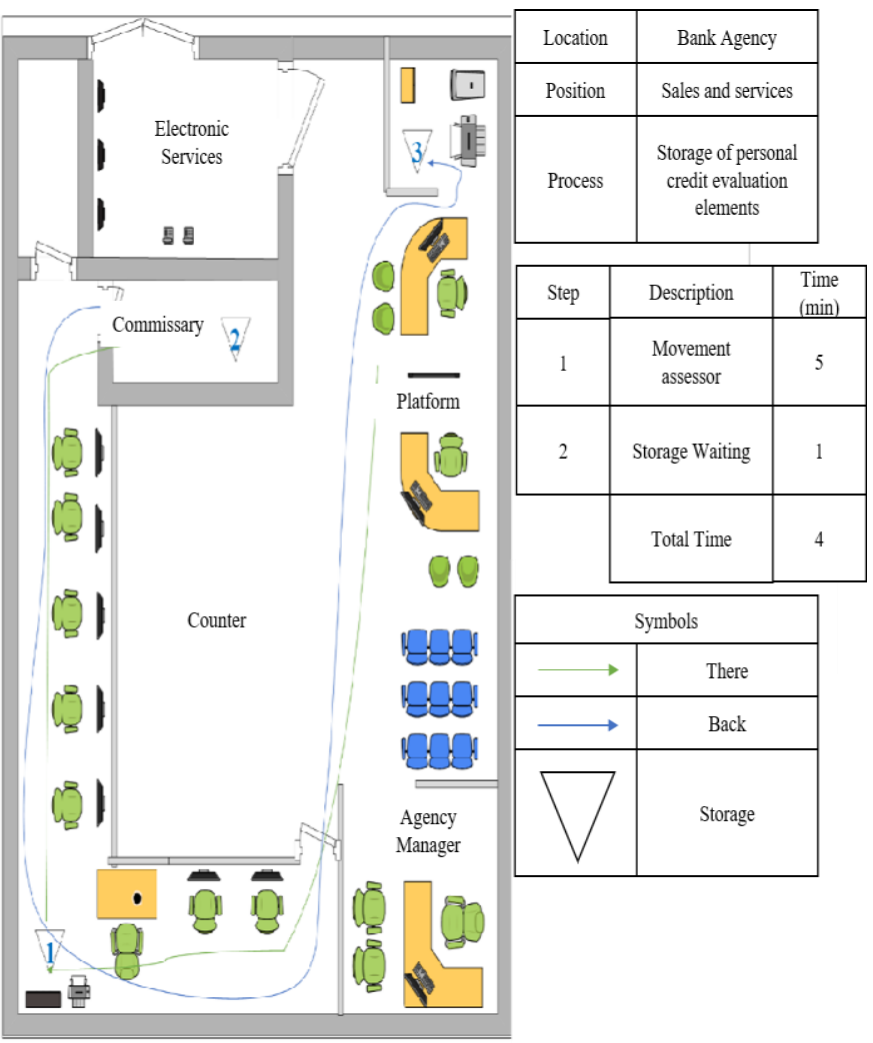

Fig. 8 Proposed stock Runtime of the Sales and Service Advisor Spaghetti Diagram

The fourth improvement, suggests modeling the process improvement proposal, where the simulation of the process improvement proposal is executed, in which the arrival of 20 applications to centralized evaluation are verified and the average amount of 20 are sent, and of which, the centralized area of personal credit approves 16 applications.

Lastly, in the fifth improvement, which is validated in monetary terms in Figure 9, when the proposed process is executed, there is an annual cost of $\mathrm{S} / .678,060.50$, well below the annual cost with the previous process by $\mathrm{S} /$. $1,748,195.00$. 


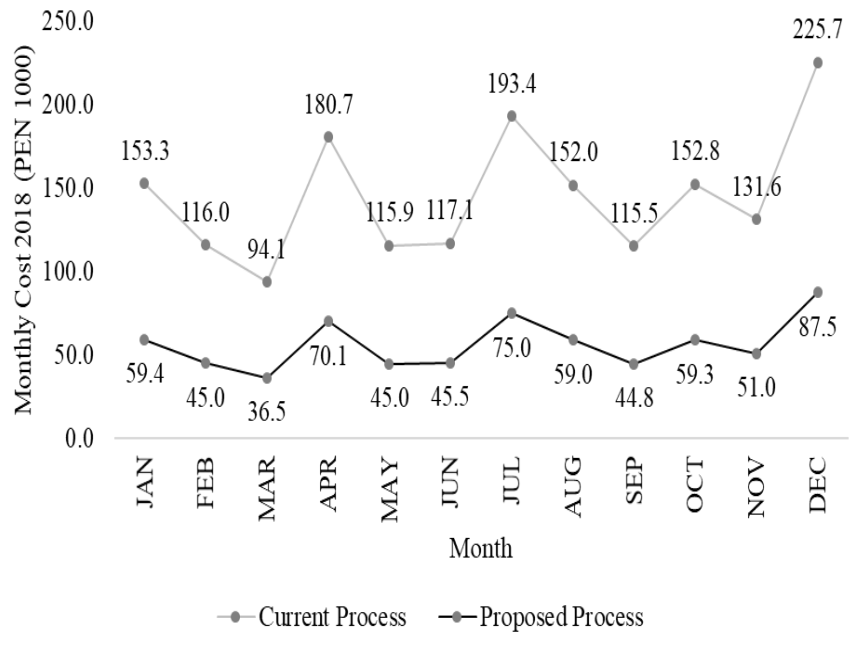

Fig. 9 Comparative Chart of the Previous Process vs. the Proposed Process

By applying the Six Sigma methodology, the personal credit evaluation process was simplified from 14 to 12 activities by identifying activities that do not add value to the process as well as, for example, duplication by waste type. Likewise, the application of the time study through the value stream mapping methodology reduced the personal credit application response time from 2393 minutes to 1049 minutes. Additionally, the proposed new process was standardized through the procedure sheet and process sheet to document the flow diagram.

The runtime of the sales and service advisors to stock the necessary materials and documentation to evaluate personal credit applications was reduced from 24 to 4 minutes, because of the analysis of the Spaghetti diagram to identify time lost in the runtimes at each storage point. In the handling of personal credit requests by centralized evaluation with the proposed process, 16 requests are arrested and compared with the previous process by one request.

\section{CONClusions}

This study outlines the benefits and the tools to be used for the process analysis and data through the LSS methodology for the banking institution. The present study identified that banking entities in Peru do not usually use methodologies for improving their processes, and thus, incorporating the LSS in the banking institution under study is a competitive advantage, which must be replicated to other retail and wholesale banking financial products.

The case study presented is an example of how the Lean Six Sigma methodology takes advantage of technology by applying Six Sigma tools for data analysis, helping to improve results in times and number of credit servicing in banking products, as well as easy the generation of a culture of continuous improvement in a banking institution.

\section{REFERENCES}

[1] “Crédito al Sector Privado se expandió 6.7\% al cierre de 2017”. Notas Informativas, pp. 1. Año 2018. Consulta: 13 de Julio 2019.

[2] Islam, Samsul (2016) Credit Card Account Opening Excellence Using Six Sigma Methodology. Consulta: 14 de Julio 2019.

[3] Shamsuzzaman, M. y Alzeraif, M. y Alsyouf, I. y Khoo, M. (2018) Using Lean Six Sigma to improve mobile order fulfilment process in a telecom service sector. Consulta: 14 de Julio 2019.

[4] Raid, A. y Saeed, A. y Shereen, A. (2016) Reducing Operational Downtime in Service Processes: A Six Sigma Case Study. Consulta:14 de Julio 2019.

[5] Maqbool, Y. y Zeeshan, M. y Hussain, A. y Ali,H. y Javed, S. y Saad, M. y Aamir, M. y Mumtaz, S. y Haider, M. y Atif, M. (2019) An Implementation Framework to Attain 6R Based Sustainable Lean Implementation- A Case Study. Consulta: 15 de Julio 2019.

[6] Jiju, A y Vijaya S. (2015) Six-sigma for improving Top-Box Customer Satisfaction score for a banking call centre. Consulta:15 de julio 2019.

[7] Vinodh, S. y Ben Ruben, R. y Asokan, P. (2018) Lean Six Sigma with environmental focus: review and framework. Consulta: 17 de Julio 2019.

[8] Fadoua, A. (2018) Lean service practices in the Moroccan banking. Consulta: 16 de Julio 2019

[9] Sunder M, V., Ganesh, L.S., Marathe, R.R. (2019) Lean Six Sigma in consumer banking - an empirical inquiry. Consulta: 16 de Julio 2019.

[10] Sunder M., V. (2016). Lean six sigma project management - a stakeholder management perspective. Consulta: 16 de Julio 2019.

[11] Sunder M., V. (2016). Lean six sigma project management - a stakeholder management perspective. Consulta: 16 de Julio 2019.

[12] Romero Romero, José A. (2019) Propuesta de mejora del proceso de tiempos de respuesta a solicitudes de Crédito Personal en Evaluación Centralizada de una Institución Bancaria Aplicando la Metodología Lean Six Sigma. "Universidad Peruana de Ciencias Aplicadas (UPC), Lima, Peru, 2019. 